\title{
Addressing the Missing Link between Knowledge Sharing \& NPO Effectiveness: The Mediation Effect of Trust
}

\author{
Nurul Hidayana Mohd Noor, Siti Hajar Abu Bakar Ah, and Mohd Awang Idris
}

\begin{abstract}
This present study main objective is to examine the mediating effect of culture of trust on the relationships between knowledge sharing behavior and external and internal effectiveness of nonprofit organization (NPO). We employed a structured questionnaire in approaching 299 social worker representing 34 NPOs in Klang Valley, Malaysia. The framework is analyzed using Structural Equation Modeling and Baron and Kenny's (1986) mediation analysis. Our first path analysis indicated that trust does not mediate the proposed relationships. On the other hand, the second path analysis has proved the partial mediation effect of trust towards the proposed relationships. This study contributes to the current nonprofit literature that suffers from a paucity of research.
\end{abstract}

Index Terms-Trust, knowledge sharing, external effectiveness, internal effectiveness, mediation effect.

\section{INTRODUCTION}

"The NPO neither supplies goods or services not controls. Its product is neither a pair of shoes nor an effective regulation. Its product is a changed human being. The NPOs are human-change agents" [1].

Nonprofit organization (NPO) plays an imperious role in the most societies. As a change agent, they are equally significance as private and public organization because they offering important services typically less provided by both organizations such as health awareness, emotional support, and social welfare [2]. Consistent with their prevalent role, NPOs nowadays are required for exploring the effective service management due to the several challenges. According to online article written by Suzanne Peery and her colleagues, there are five main challenges for NPOs. These include: 1) the challenges in balancing stakeholders demand and need, 2) a reduction in the government aid, 3 ) the demand to show more appealing results, 4) the requirement for efficiency and effectiveness, and 5) the innovation and competition from social enterprises [3]. Thus, in addressing these challenges, we proposed the utilization of knowledge sharing in order to help them to remain competitive and effective. As highlighted

Manuscript received June 19, 2015; revised February 10, 2016. This paper is part of a doctoral work at University of Malaya, Malaysia. The financial supports for the study have been provided by the MARA Technology of University (UiTM), Malaysia and Malaysian Ministry of Education.

Nurul Hidayana Mohd Noor and Siti Hajar Abu Bakar Ah are with the Department of Social Justice \& Administration, University of Malaya, 50603 Kuala Lumpur, Malaysia (e-mail: nurulhidayana@yahoo.com, shajar@um.edu.my).

Mohd Awang Idris is with the Department of Anthropology \& Sociology, University of Malaya, 50603 Kuala Lumpur, Malaysia (e-mail: idrma@um.edu.my). by Peter Drucker (1996), knowledge is the only source of competitive advantage [4]. In proposing our mediating variable as intervening variable towards the relationship between knowledge sharing and NPO effectiveness, we refer to social exchange theory (SET) as our main guidance. The SET suggests that social behavior is the result of an exchange process and trust has been recognized as one factor underlying within this theory. McEvily et al. (2003) also stated that the level of trust affects the extent people to share knowledge [5]. Thus, in order to promote active knowledge sharing, trust is act as one of the most importance enabler.

In addition, based on the syntheses from previous knowledge management (KM) literature, we discover there is limited area covers by nonprofit researcher. For example, Jackson and his colleagues have successfully identified the barriers for knowledge sharing in NPO. The results revealed that communication, insufficient understanding, and a lack of rewards have hindered the effective knowledge sharing [6]. However, their study only focuses on single case unit (i.e. sport association) and does not relate the study with the NPO effectiveness. Next, Gillian et al. (2014) conducted the evaluation of knowledge sharing management based on event implementation [7]. The findings revealed that trust between volunteers and their intention to share information appeared to be dependent. Even though, Gillian et al.'s (2014) study has also focused on a single NPO [7], the study findings have enthuse us to propose trust as mediating factor in facilitating the relationships between knowledge sharing and NPO external and internal effectiveness. We believe that there is a paucity of studies published that have specifically addressed the proposed framework. This permits more systematic inquiry especially in the context of Malaysian NPO.

\section{THEORETICAL BACKGROUND \& HYPOTHESES DEVELOPMENT}

Knowledge sharing occurs when an individual is willing to assist as well as to learn from others in the development of new competencies [8]. Knowledge sharing behavior refers to the extent that people share strategic knowledge with their colleagues through process of mutually exchanging knowledge and jointly creating new knowledge [9]. This mean knowledge sharing involves two-way processes which are knowledge donating and knowledge collecting. For example, an employee knows about new information, him or her then, share the information to his or her colleague. Then, his or her colleague digests the knowledge for his or her competencies improvement. Even though the knowledge sharing occurs in a two-way communication, the issue need to be concerned by the management is regarding the full or 
partial knowledge sharing. Full knowledge sharing refers to a full knowledge disclosure while, on the other hand, partial knowledge sharing occurs when the knowledge is unshared or limited share due to the issue of confidentiality and risk hindrance [10]. Thus, situational or environmental factor may influence what and how knowledge is being shared.

Despite the differences in the orientation of knowledge sharing, knowledge sharing offers several benefits to the organization and a plethora of study has agreed that it contributes towards organizational effectiveness [11]. Knowledge sharing also promotes employees satisfaction, foster continuous improvement, and increase organizations' innovative ability [12], [13]. In order to ensure active knowledge sharing process, there are several factors that can help to facilitate the process and based on the ample evidence from previous study, trust is prominently highlighted as the main factor [14]. In discussing this relationship, we refer to the social exchange theory (SET). As according to the SET, the basic tenets of influencing people behavior is by inculcating the concept of trust, loyal, and mutual commitments [15]. Furthermore, the SET stipulates that certain workplace antecedents lead to interpersonal connections, referred to as social exchange relationships [15]. The higher level of social exchange will motivate employees to more engage in a positive behavior. In our case is knowledge sharing. Social identification may encourage knowledge sharing, since identification acts as a driver, influencing the motivation to share knowledge [16] and trust has been identified as an element of social identification.

Trust can be defined as a dispositional and enduring individual characteristic, or as an aspect of the relationship between two persons, a person and a team, or a person and an organization [17]. Trust had a direct effect on organizational performance [18], a significant factor to employee productivity, and strengthens employee capability to manage problems [19]. Trust is important because it facilitate greater process of tacit knowledge sharing. Generally, there are two types of knowledge which are: 1) explicit knowledge and 2) tacit knowledge [20]. Explicit knowledge can be share and documented easily. For example, documented information, memos, email, and presentation slide. While, tacit knowledge is hardly to be documented because it is embedded in the brain of knowledge carrier [21]. For example are problem solving and analytical skills. Thus, when these skillful staffs leave the organization, the organization itself wills loss the valuable assets (i.e., knowledge). In resolving this problem, a plethora of research has discovered that tacit knowledge sharing may depend on the extent that employees are trusted recipients and sources [22]. Furthermore, Renzl (2008) highlighted that trust help to facilitate knowledge sharing behavior by reducing fear of losing one's value, and at the same time improving the individual's motivation to document knowledge [23]. In order to create a trust culture within workplace, Cummings and Bromiley (1996, p. 303) clarified that a group must a) makes a good-faith effort to behave in accordance with any commitments both explicit or implicit, b) is honest in whatever negotiations that preceded such commitments, and c) does not take excessive advantage of another even when the opportunity is available [24]. Thus, we proposed the following hypotheses:
H1: Knowledge sharing significantly predicts trust

H2: Trust significantly predicts external effectiveness

H3: Knowledge sharing significantly predicts external effectiveness

H4: Trust significantly predicts internal effectiveness

H5: Knowledge sharing significantly predicts internal effectiveness

H6: Trust mediates the relationship between knowledge sharing and external effectiveness

H7: Trust mediates the relationship between knowledge sharing and internal effectiveness

The research model for this study is shown on Fig. 1.

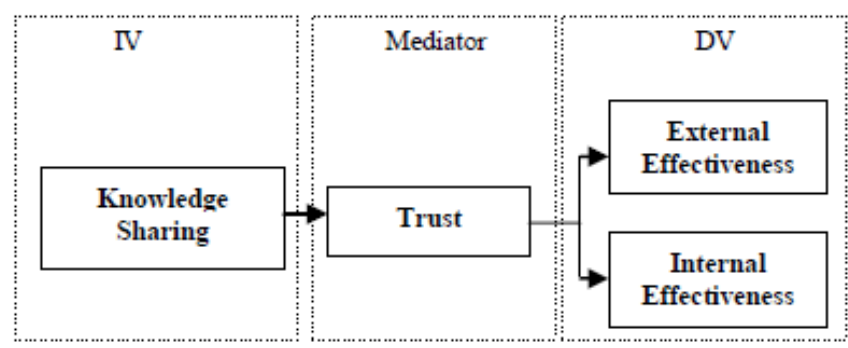

Fig. 1. Research model.

\section{RESEARCH METHODOLOGY}

\section{A. Data Collection and Participants}

Using a self-administered questionnaire, we approached 340 social worker from 34 NPOs located in Klang Valley, Malaysia. This area was chosen due to large number of NPOs population [25]. Following rule of thumb for determining sample size as proposed by Roscoe (1975), for most research, a sample size larger than 30 and less than 500 is appropriate [26]. A total of 299 responses were received. It constitutes a response rate of 87.9 percent $(\%)$. The respondents in the study included a composition of male $(56.2 \%)$ and female (43.8\%). More than half of the respondents' age group was $\geq$ $30(57.2 \%)$ whereas rest those was $<30(42.8 \%)$. In respect to education, about $96 \%$ percent of the participant held diplomas or university degrees. Many of the respondents were part-time staffs $(50.5 \%)$ and the rest of $49.5 \%$ were full-time staffs.

\section{B. Measurement}

All measures used in this study were drawn from prior studies in the related literatures. To measure knowledge sharing, we adapted from a 10-items scale developed by van den Hooff and de Ridder (2004) [9]. Next, trust (6 items) was measured based on scale developed by Lee and Choi (2003) [14]. Then, in evaluating the external effectiveness, we adopted 7-items scale developed by Espirito (2001) [as cited in 27]. Finally, internal effectiveness was measured using 13-items scale also developed by Espirito (2001) [as cited in 27].

\section{Data Analysis}

Before main analyses, the descriptive statistics using IBM SPSS 20 were conducted to examine in the level of all variables, to clean the data, and to inspect the several statistical assumptions [28]. The main data analysis was done using Structural Equation Modeling (SEM-AMOS 18). In the first phase, we conducted a pooled Confirmatory Factor 
Analysis (CFA) in order to assess the study measurement model. Using SEM-AMOS, the issue of validity and reliability need to be addressed first through the measurement model stage. For the purpose of our study, we followed the several index categories that highly used by previous researchers. These include: 1) Chisq/df ( $p>.05), 2)$ RMSEA $(<.08), 3)$ GFI (>.90), 4) CFI (>.90), and 5) TLI (>.90). Furthermore, we also followed Fornell and Larcker's (1981) suggestions which include: 1) all item loadings should be significant and exceed .70, 2) an acceptable Composite Reliability (CR) value for each construct should exceed .70, and 3) Average Variance Extracted (AVE) for each construct should exceed .70 [29].

In evaluating the mediation effect, we followed Baron and Kenny's (1986) three steps which are: 1) X (independent variable) is significantly correlated with $\mathrm{Y}$ (dependent variable), 2) $\mathrm{X}$ is significantly correlated with $\mathrm{M}$ (mediating variable), and 3) $\mathrm{M}$ is significantly correlated with $\mathrm{Y}$. To establish that $\mathrm{M}$ completely mediates the $\mathrm{X}-\mathrm{Y}$ relationship, the effect of $\mathrm{X}$ on $\mathrm{Y}$ controlling for $\mathrm{M}$ (path c') should be insignificant and if is not, and then partial mediation is indicated [30]. We confirmed the results using the Sobel test. Fig. 2 summarized the mediation model of this study.

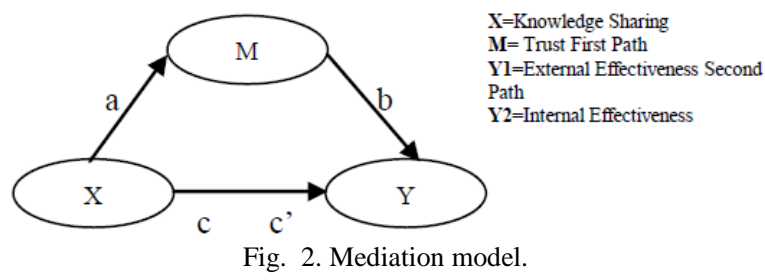

\section{RESULTS AND ANALYSIS}

\section{A. Measurement Model}

We resolved the redundant items problem by setting them to be free parameter estimate by using double-headed arrow and re-specify the model. Table I presented the model fit results of the Confirmatory Factor Analysis (CFA) after re-specify.

TABLE I: FITNESS INDEXES FOR THE MEASUREMENT MODEL

\begin{tabular}{|c|c|c|c|c|c|}
\hline Name of Category & Index & Value & Comments & & \\
\hline \multirow[t]{2}{*}{ 1.Absolute fit } & $\begin{array}{l}\text { RMSE } \\
\text { A }\end{array}$ & .76 & $\begin{array}{l}\text { The required } \\
\text { achieved }\end{array}$ & level & is \\
\hline & GFI & .90 & $\begin{array}{l}\text { The required } \\
\text { achieved }\end{array}$ & level & is \\
\hline \multirow[t]{2}{*}{ 2.Incremental fit } & CFI & .93 & $\begin{array}{l}\text { The required } \\
\text { achieved }\end{array}$ & level & is \\
\hline & TLI & .92 & $\begin{array}{l}\text { The required } \\
\text { achieved }\end{array}$ & level & is \\
\hline 3.Parsimonous fit & $\begin{array}{l}\text { Chisq/d } \\
\mathrm{f}\end{array}$ & 4.32 & $\begin{array}{l}\text { The required } \\
\text { achieved }\end{array}$ & level & is \\
\hline
\end{tabular}

Note: $N=299$; RMSEA=Root Mean Square Error of Approximation; GFI= Goodness of Fix Index; CFI= Comparative Fix Index; TLI= Tucker-Lewis Index; Chisq/df=Chi Square/Degree of Freedom.

Next, Table II shows the overall measurement results for the proposed model.

All factor loadings for the construct were above .70. Thus, no items were deleted from the original model. Cronbach alpha reliability for all scales was acceptable, range from .75 to .84 . Moreover, the readings of composite reliability of the latent variables were above .70 . Therefore, all latent variables have good reliability. Final column showed all latent constructs AVE values were above .70. Thus, the assumptions for the measurement model were fulfilled [29].

TABLE II: OvERALL MEASUREMENT MODEL ANALYSIS

\begin{tabular}{|c|c|c|c|c|c|}
\hline Construct & Items & $\begin{array}{l}\text { Factor } \\
\text { Loading }\end{array}$ & $\begin{array}{l}\text { Cronbach's } \\
\text { Alpha }\end{array}$ & $\mathrm{CR}$ & AVE \\
\hline Trust & $\begin{array}{l}\text { T1 } \\
\text { T2 } \\
\text { T3 } \\
\text { OC4 } \\
\text { OC5 } \\
\text { OC6 }\end{array}$ & $\begin{array}{l}.97 \\
.96 \\
.92 \\
.89 \\
.85 \\
.98\end{array}$ & .75 & .97 & .86 \\
\hline $\begin{array}{l}\text { Knowledge } \\
\text { Sharing }\end{array}$ & $\begin{array}{l}\text { KS1 } \\
\text { KS2 } \\
\text { KS3 } \\
\text { KS4 } \\
\text { KS5 } \\
\text { KS6 } \\
\text { KS7 } \\
\text { KS8 } \\
\text { KS9 } \\
\text { KS10 }\end{array}$ & $\begin{array}{l}.87 \\
.94 \\
.94 \\
.91 \\
.92 \\
.93 \\
.90 \\
.77 \\
.87 \\
.89\end{array}$ & .84 & .98 & .80 \\
\hline $\begin{array}{l}\text { External } \\
\text { Effectiveness }\end{array}$ & $\begin{array}{l}\text { EX1 } \\
\text { EX2 } \\
\text { EX3 } \\
\text { EX4 } \\
\text { EX5 } \\
\text { EX6 } \\
\text { EX7 }\end{array}$ & $\begin{array}{l}.99 \\
.99 \\
.97 \\
.99 \\
.99 \\
.97 \\
.92\end{array}$ & .82 & .97 & .95 \\
\hline $\begin{array}{l}\text { Internal } \\
\text { Effectiveness }\end{array}$ & $\begin{array}{l}\text { IN1 } \\
\text { IN2 } \\
\text { IN3 } \\
\text { IN4 } \\
\text { IN5 } \\
\text { IN6 } \\
\text { IN7 } \\
\text { IN8 } \\
\text { IN9 } \\
\text { IN10 } \\
\text { IN11 } \\
\text { IN12 } \\
\text { IN13 }\end{array}$ & $\begin{array}{l}.94 \\
.98 \\
.99 \\
.97 \\
.96 \\
.93 \\
.99 \\
.94 \\
.93 \\
.98 \\
.97 \\
.98 \\
.95\end{array}$ & .81 & .99 & .92 \\
\hline
\end{tabular}

Note: $N=299$; Factor loadings $>.70$; all variables reliabilities value were accepted $(\alpha>.70)$; all variables Composite Reliability (CR) were accepted $(\mathrm{CR} \geq .70)$; all variables Average Variance Extracted (AVE) were accepted (AVE $\geq .70)$.

Since convergent validity was achieved, it is appropriate to test for discriminant validity. Discriminant validity shows the extent to which a construct is truly distinct from other constructs [31]. The diagonal values (in bold) are the square root of AVE while other values are the correlation between the respective constructs and a diagonal value in bold is must higher than the values in its row and column. Based on Table III, this study fulfilled the assumption of discriminant validity.

TABLE III: CFA RESULTS SUMMARY FOR DISCRIMINANT VALIDITY

\begin{tabular}{lllll}
\hline \hline Construct & 1 & 2 & 3 & 4 \\
\hline 1.Trust & $\mathbf{. 9 3 0}$ & & & \\
2.Knowledge Sharing & .580 & $\mathbf{. 8 9 6}$ & & \\
3.External Effectiveness & .756 & -.038 & $\mathbf{. 9 7 6}$ & \\
4.Internal Effectiveness & .542 & .205 & .550 & $\mathbf{. 9 6 1}$ \\
\hline \hline
\end{tabular}

Note: $N=299$; Values in boldface are square root of AVE and others are correlations.

\section{B. Structural Model}

Based on Table IV, the first regression path showed the regression weight for knowledge sharing in the prediction to trust was significantly direct effect $(\beta=.61, p<.001)$. Thus, hypothesis 1 was accepted. Next, we examined the first path 
model. The second regression showed the trust was insignificantly direct effect on external effectiveness $(\beta=-.04$, $p>.05)$. Thus, hypothesis 2 was rejected. In the third regression, the direct effect of knowledge sharing to external effectiveness was significant $(\beta=.85, \quad p<.001)$. Thus, hypothesis 3 was accepted. Based on Baron and Kenny (1986), we can conclude that trust does not mediate the relationship between knowledge sharing and NPO external effectiveness [30]. In other words, trust does not influence the proposed relationship. Thus, hypothesis 6 was rejected.

TABLE IV: CAUSAL EFFECT REGRESSION PATH

\begin{tabular}{|c|c|c|c|c|c|c|c|}
\hline \multirow[t]{2}{*}{ Path } & & & \multicolumn{3}{|c|}{ Direct Effect } & \multirow[t]{2}{*}{$\overline{a \mathrm{ab}}$} & \multirow[t]{2}{*}{$\mathrm{c}$} \\
\hline & & & $\beta$ & S.E. & $p$ & & \\
\hline Trust & $<$ & KS (path a) & .61 & .06 & $* * *$ & & \\
\hline \multicolumn{8}{|c|}{ External Effectiveness } \\
\hline EX & $<<$ & Trust (path b) &.- .04 & .05 & .44 & & \\
\hline EX & $<$ & KS (path c') & .85 & .06 & $* * *$ & -.03 & .83 \\
\hline \multicolumn{8}{|c|}{ "Internal Effectiveness } \\
\hline$\overline{\mathrm{IN}}$ & << & "Trust (path b) & . .18 & ב.05 & "*** & & \\
\hline IN & $<$ & KS (path c') & .51 & .05 & $* * *$ & .11 & .63 \\
\hline
\end{tabular}

Note: $\quad N=299 ; \quad$ KS=Knowledge $\quad$ Sharing; Trust=Trust; $\quad$ EX=External Effectiveness; IN= Internal Effectiveness; $a b=i n d i r e c t$ path; $c=$ total path, $* * * p<.001$.
Then, we examined the second path model. The fourth regression showed the trust was significantly direct effect on internal effectiveness $(\beta=.18, p<.001)$. Thus, hypothesis 4 was accepted. In the fifth regression, the direct effect of knowledge sharing to internal effectiveness was significant $(\beta=.51, p<.001)$. Thus, hypothesis 5 was accepted. Based on Baron and Kenny (1986), we can conclude that trust partially mediates the relationship between knowledge sharing and NPO internal effectiveness [30]. Thus, hypothesis 7 was accepted. This is because when we combined mediating variable (trust) within the model, the direct effect from independent variable (knowledge sharing) to dependent variable (internal effectiveness) is still significant. In other words, NPO still can achieve internal effectiveness without trust but trust act as factor to enhance the process. Full mediation is only achieved if the direct effect is insignificant. Once the analysis was completed, the Sobel test was used to test whether the mediation effect was statistically significant [32]. The result revealed that the statistical significance value is .00. Thus, mediation effect of knowledge sharing for the second path was confirmed. These results were summarized in Fig. 3.

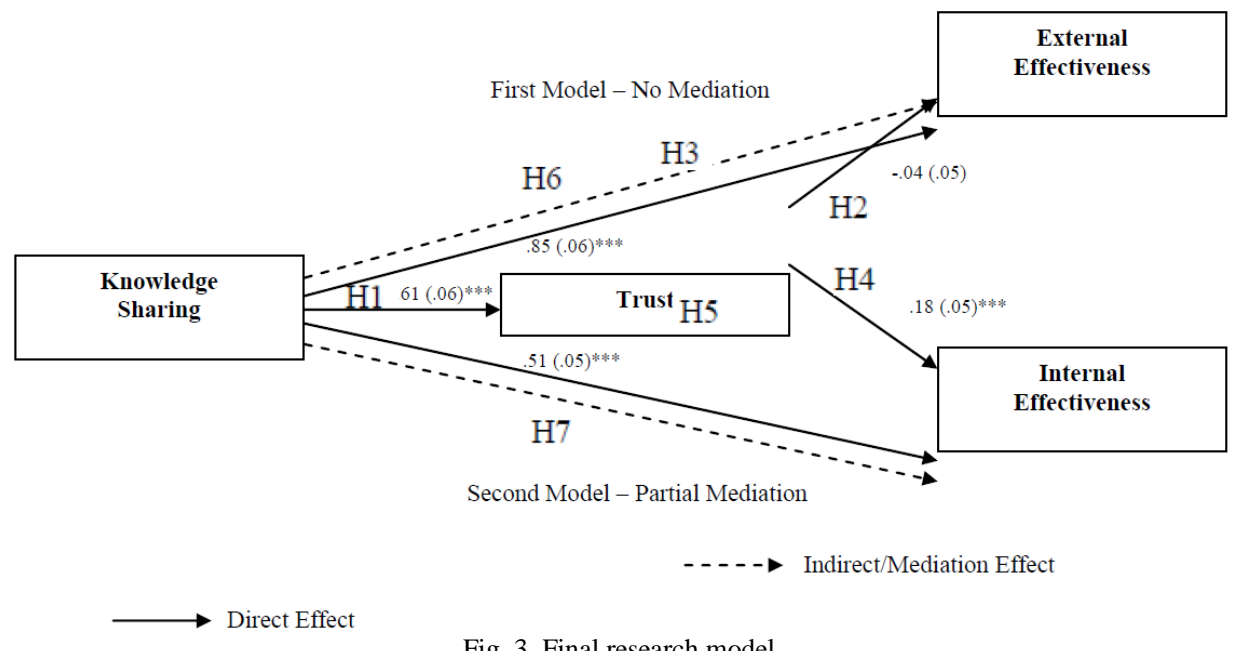

Fig. 3. Final research model.

\section{DISCUSSION AND CONCLUSION}

The objective of our study is to contribute to clarification of the mediation effect of trust that may affect the association between knowledge sharing and NPO external and internal effectiveness. Knowledge sharing has the potential effect to enhance employees' productivity, and organizational innovation capacity and effectiveness [13]. Our findings have revealed that the outcomes of knowledge sharing definitely influenced both NPO external and internal effectiveness. The results also revealed that trust mediates the relationship between knowledge sharing and internal effectiveness. As Nonaka and Takuechi (1995) explained, trust is crucial for the creation of knowledge sharing atmosphere in teams and organizations [20]. Unfortunately, as not expected, our findings have revealed that trust does not mediate the relationship between knowledge sharing and external effectiveness. Logically in explaining this result, we believe this is happens because trust is more closely associates with the internal performance (e.g., intervention strategy, goal determination, and communication), rather than external performance (e.g., the accomplishment of overall goals and customer satisfaction).

Our study has several methodological and practical implications. Previous researches have already analyzed the direct effect of the study variables which try to ascertain whether knowledge sharing has effects on organizational effectiveness. We depart from those researches by analyzing the mediating role of trust as an additional variable that may clarify the nature of the relationship between both of them. This third variable may explains whether and to what extent those effects exist to how and why they exist. Next, our findings also offer several practical implications for the NPO management. A body of knowledge has revealed that knowledge sharing behavior is enhancing through encouragement rather than forced [33]. As a result, there are two main schemes in investigating knowledge sharing behavior. First, knowledge sharing is based on individual personality. Second, knowledge sharing can be facilitating through organizational intervention. Thus, we encouraged the NPOs management to concern on organizational intervention that may help in encouraging knowledge sharing behavior. As 
supported by a body of knowledge, a successful knowledge sharing is depending on internal organizational structures and processes that promote cooperation and the transference of knowledge [34]. One way to do this is reward. Lam and Lambermont-Ford (2010) suggested that the management can encourage employees to share knowledge by motivating them through reward either intrinsic or extrinsic [35]. Over time, consistent rewards could help develop team spirit, and lead to team sharing and learning process. In utilizing trust, the management may play a key role in inculcating trust culture [36]. Through time, these actions may shape a person's level of trust and making him or her more prone to share knowledge. This study has necessarily involved a compromise that results in a limitation in the research methods. First, the sample frame of this study only focused on social worker representing NPOs located in Klang Valley area, Malaysia. The generalizability of this study in other areas or states is needed. Second, data were cross-sectional and collected via a single source. Thus, we cannot establish causality between the variables and self-administered questionnaire raises common method bias concerns. Finally, we focused exclusively on trust as a mediator. Future research could analyze the role of other variables in the relationship between knowledge sharing and NPO effectiveness.

\section{ACKNOWLEDGMENT}

We are indebted to the Malaysian Ministry of Higher Education and MARA Technology of University (UiTM), Malaysia for providing funding for this study. We also would like to thank to the anonymous reviewers for the reviews as well as to the social workers for their generous participation.

\section{REFERENCES}

[1] P. F. Drucker, Managing the Non-Profit Organization: Practices and Principles, New York: Harper Collins, 1990.

[2] L. Duque-Zuluaga and U. Schneider, "Market orientation and organizational performance in the nonprofit context: Exploring both concepts and the relationship between them," Journal of Nonprofit Public Sector Marketing, vol. 19, no. 2, pp. 25-47, 2006.

[3] P. Suzanne, P. Caroline, and W. Nicole. (January 4, 2012). 5 challenges for the nonprofit world: The Chronicle of Philanthropy. [Online]. Available: https://philanthropy.com/article/5-Challenges-for-the-Nonprofit/1573 87

[4] P. F. Drucker, Managing in a Time of Great Change, New York: Truman Talley Books/Dutton, 1996.

[5] B. McEvily, V. Perrone, and A. Zaheer, "Trust as an organizing principle," Organization Science, vol. 14, pp. 91-103, 2003.

[6] T. W. Jackson, C. J. Hinde, P. Parboteeah, R. Timms, and R. Washington, "The barriers to knowledge sharing within a third sector sport organization," presented at the 13th European Conference on Knowledge Management, Cartagena, Spain, 2012.

[7] R. Gillian, O. E. Eva, and N. Michael, "Knowledge management in the voluntary sector: A focus on sharing project know-how and expertise," Knowledge Management Research \& Practice, vol. 12, pp. 351-361, 2014.

[8] P. Senge, "Some thoughts at the boundaries of classical systems dynamics: Structuration and wholism," presented at the 2012 16th International Conference of the System Dynamics Society, Que'bec City, Que'bec, Canada, 1998

[9] B. van den Hooff and J. A. De Ridder, "Knowledge sharing in context: The influence of organizational commitment, communication climate and CMC use on knowledge sharing," Journal of Knowledge Management, vol. 8, no. 6, pp. 117-130, 2004.

[10] G. A. Bigley and K. H. Roberts, "The incident command system: High-reliability organizing for complex and volatile task environments," Academy of Management Journal, vol. 44, no. 6, pp. 1281-1299, 2001.

[11] F. Olivera, "Memory systems in organizations: An empirical investigation of mechanisms for knowledge collection, storage and access," The Journal of Management Studies, vol. 37, no. 6, pp. 811-832, 2000.

[12] L. Cardoso, A. Meireles, and C. F. Peralta, "Knowledge management and its critical factors in social economy organizations," Journal of Knowledge Management, vol. 16, no. 2, pp. 267-284, 2012.

[13] A. H. Gold, A. Malhotra, and A. H. Segars, "Knowledge management: An organizational capabilities perspective," Journal of Management Information Systems, vol. 18, no. 1, pp. 184-214, 2001.

[14] H. Lee and B. Choi, "Knowledge management enablers, processes, and organizational performance: An integrative view and empirical examination," Journal of Management Information System, vol. 20, pp. 179-228, 2003

[15] R. Cropanzano, Z. S. Byrne, D. R. Bobocel, and D. R. Rupp, "Moral virtues, fairness heuristics, social entities, and other denizens of organizational justice," Journal of Vocational Behaviour, vol. 58, pp. 164-209, 2001.

[16] C. M. Chiu, M. H. Hsu, and E. T. G. Wang, "Understanding knowledge sharing in virtual communities: An integration of social capital and social cognitive theories," Decision Support Systems, vol. 42, no. 3, pp. 1872-1888, 2006.

[17] M. Yakovleva, R. R. Reilly, and R. Werko, "Why do we trust? Moving beyond individual to dyadic perceptions," Journal of Applied Psychology, vol. 95, no. 1, p. 79, 2010

[18] J. Davis, F. D. Schoorman, R. Mayer, and H. Tan, "Trusted unit manager and business unit performance: Empirical evidence of a competitive advantage," Strategic Management, vol. 21, no. 1, pp. $563-576,2000$.

[19] J. Mishra and M. A. Morrissey, "Trust in employee/employer relationships: A survey of west Michigan managers," Public Personnel Management, vol. 19, no. 4, pp. 443-461, 1990.

[20] I. Nonaka and H. Takeuchi, The Knowledge-Creating Company, New York: Oxford University Press, 1995

[21] R. Cross and L. Baird, "Technology is not enough: Improving performance by building organizational memory," Sloan Management Review, vol. 41, no. 3, pp. 69-78, 2000

[22] P. S. Adler, "Market, hierarchy, and trust: The knowledge economy and the future of capitalism," in Critical Management Studies: A Reader, C. Grey and H. Willmott, Eds. Oxford University Press, 2000, pp. 214-234

[23] B. Renzl, "Trust in management and knowledge sharing: The mediating effects of fear and knowledge documentation," Omega, vol. 36, no. 2, pp. 206-220, 2008

[24] L. L. Cummings and P. Bromiley, "The organizational trust inventory (OTI): Development and validation," in Trust in Organizations, R Kramer and T. Tyler, Eds. Thousand Oaks, CA: Sage, 1996, pp 302-330.

[25] Registrar of Society (ROS), Annual Report 2011, Federal State of Putrajaya, Malaysia, Registrar Society of Malaysia, 2012.

[26] J. T. Roscoe, Fundamental Research Statistics for the Behavioural Sciences, 2nd ed., New York: Holt Rinehart \& Winston, 1975.

[27] N. Mussalam, "Examining the perceived internal and external effectiveness of NGOs in the Palestinian territories: The role of complexity, resilience, and job adaptability," Ph.D. dissertation, New York, US: Columbia University, 2011.

[28] U. Sekaran, Research Methods for Business: A Skill-Building Approach, 4th ed., New York: Wiley, 2003.

[29] C. Fornell and D. F. Larcker, "Evaluating structural equation models with unobservable variables and measurement error," Journal of Marketing Research, vol. 18, no. 1, pp. 39-50, 1981.

[30] R. M. Baron and D. A. Kenny, "The moderator-mediator variable distinction in social psychological research: Conceptual, strategic, and statistical considerations," Journal of Personality and Social Psychology, vol. 51, pp. 1173-1182, 1986.

[31] J. F. Hair, W. C. Black, B. J. Babin, and R. E. Anderson, Multivariate Data Analysis, 7th ed., Upper Saddle River, New Jersey: Prentice Hall, 2010.

[32] M. E. Sobel, "Asymptotic intervals for indirect effects in structural equations models," in Sociology Methodology, S. Leinhart, Ed., San Francisso: Jossey-Bass, 1982.

[33] G. W. Bock, R. W. Zmud, Y. G. Kim and J. N. Lee, "Behavioural intention formation in knowledge sharing: Examining the roles of extrinsic motivators, social-psychological forces, and organizational climate," MIS Quarterly, vol. 29, no. 1, pp. 87-111, 2005. 
[34] J. Child and R. G. McGrath, "Organizations unfettered: Organizational form in an information intensive economy," Academy of Management Journal, vol. 44, no. 6, pp. 1135-1148, 2001.

[35] A. Lam and J.-P. Lambermont-Ford, "Knowledge sharing in organizational contexts: A motivation-based perspective," Journal of Knowledge Management, vol. 14, no. 1, pp. 51-66, 2010.

[36] A. C. Costa and N. Anderson, "Measuring trust in teams: Development and validation of a multifaceted measure of formative and reflective indicators of team trust," European Journal Organizational Psychology, vol. 20, pp. 119-154, 2011.

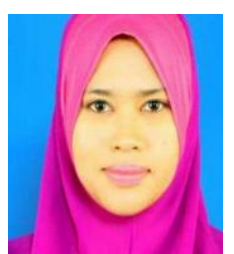

Nurul Hidayana Mohd Noor was born in Butterworth, in the state of Penang, Malaysia, on January 5,1987 . She completed her bachelor's degree in administrative science from MARA Technology of University (UiTM), Malaysia in 2010. She also completed her master degree in executive masters of administrative science from the same university in 2012. She has worked as an assistant lecturer at MARA Technology of University (UiTM) from 2010 until 2012 under graduate scheme service. She currently pursues her doctorate study at the Department of Social Justice and Administration, Faculty of Arts and Social Science, University of Malaya, Malaysia. Her research interest is third sector, particularly on NGO management; organizational culture, accountability and knowledge management.

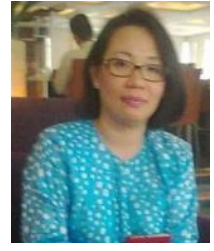

Siti Hajar Abu Bakar Ah is an associate professor at the Department of Social Justice and Administration, Faculty of Arts and Social Sciences, University of Malaya, Malaysia. Her research interests include social policy, social work and voluntary sector. She is the head of the Department of Social Administration and Justice, Faculty of Arts and Social Sciences. She is an external examiner for Medical Social Work Program, National University of Malaysia and also an active member of Family Development and Research Centre, University of Malaya. She received her Ph.D. degree from the University of Malaya, Malaysia.

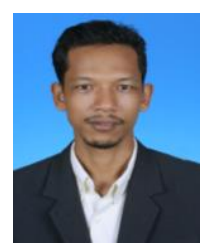

Mohd Awang Idris is a senior lecturer in work psychology, Department of Anthropology and Sociology, University of Malaya, Malaysia. His research interests include job stress, psychosocial safety climate, leadership, job engagement, workplace injuries and team performance. He publishes several papers in ISI-outlets publications, and also a reviewer for some well-known journals such as Journal Occupational and Organizational Psychology; International Journal of Stress Management, Cross-Cultural Management: An International Journal; and Journal Occupational Health. He received his Ph.D. degree in psychology from the University of South Australia, Adelaide. 